\title{
Effects of Laparoscopic Cholecystectomy on Intraocular Pressure
}

\author{
Alaa Mohammed Ibrahem Khalil'1, Waled Mahdy Nada² \\ ${ }^{1}$ General Surgery Department, Faculty of Medicine, Zagazig University, Zagazig, Egypt \\ ${ }^{2}$ Ophthalmology Department, Faculty of Medicine, Zagazig University, Zagazig, Egypt \\ Email:walednada_69@hotmail.com
}

How to cite this paper: Khalil, A.M.I. and Nada, W.M. (2017) Effects of Laparoscopic Cholecystectomy on Intraocular Pressure. Open Journal of Ophthalmology, 7, 31-36. https://doi.org/10.4236/ojoph.2017.71005

Received: January 9, 2017

Accepted: January 31, 2017

Published: February 3, 2017

Copyright (c) 2017 by authors and Scientific Research Publishing Inc. This work is licensed under the Creative Commons Attribution International License (CC BY 4.0).

http://creativecommons.org/licenses/by/4.0/

\begin{abstract}
Purpose: To evaluate the effects of laparoscopic cholecystectomy in patients with gall stones under general anesthesia using carbon dioxide $\left(\mathrm{CO}_{2}\right)$ insufflations on the intraocular pressure (IOP). Methods: The study was an observational case series, involved 24 non-glaucomatous patients with gall stones who underwent laparoscopic cholecystectomy surgery under general anesthesia using $\left(\mathrm{CO}_{2}\right)$ insufflations in the period from January 2016 to April 2016 in Zagazig University Hospitals. IOP was measured preoperatively, intra-operatively and shortly postoperatively. Interpretation of the results was performed. Results: The study revealed that IOP was elevated significantly during laparoscopic cholecystectomy surgery $(\mathrm{P}<0.001)$, as the mean preoperative IOP was $(15.21 \pm 1.61 \mathrm{mmHg})$ compared to intra-operative (24.55 \pm 6.28 $\mathrm{mmHg}$ ) and nearly returned to the normal level after 8 hours postoperatively $(16.13 \pm 2.44 \mathrm{mmHg})$. Conclusion: Laparoscopic cholecystectomy surgery elevated IOP significantly which is not favorable for glaucoma or ocular hypertension patients, especially for the old.
\end{abstract}

\section{Keywords}

Intraocular Pressure, Laparoscopic Cholecystectomy, Carbon Dioxide Insufflations

\section{Introduction}

During laparoscopic cholecystectomy, to make the gravitational displacement of the viscera away from the site of surgery, patients must put in reverse Trendelenburg position. That improves the patient's respiration. However, this position results in decreased venous return, right atria pressure, and hence falls in mean arterial pressure and cardiac output [1] [2]. Also Central Venous Pressure (CVP) increased due to abdominal carbon dioxide $\left(\mathrm{CO}_{2}\right)$ insufflations. Intraocular 
pressure (IOP) is significantly increased during laparoscopic cholecystectomy due to elevated CVP in $\mathrm{CO}_{2}$ filled abdomens in spite of reverse Trendelenburg position [3]. Also, alterations of the CVP induced by hydrostatic factors in postural changes during laparoscopic cholecystectomy, placing the head 15 degrees above or below the horizontal level, caused IOP changes [4].

Laparoscopic cholecystectomy significantly and reversibly decreases cardiac performance. Compromised patients may be at increased risk for complications not previously recognized with this procedure and also affect IOP, increasing the risk for glaucomatous patients making surgeons alarming for measuring IOP before taking the decision for laparoscopic procedure. Elevated IOP during laparoscopic cholecystectomy was mainly due to abdominal $\mathrm{CO}_{2}$ insufflations rather than other mechanisms [5] [6] [7].

This study was performed to monitor the changes in IOP that may happen during laparoscopic cholecystectomy in patients with gall stones under general anesthesia using $\mathrm{CO}_{2}$ insufflations. Also the study was limited in studying these changes without attention to other possible contributing factors that may be incriminated in this procedure.

\section{Patients and Methods}

This observational study included 24 non glaucomatous patients with gall stones who were prepared for laparoscopic cholecystectomy under general anesthesia in Zagazig University Hospitals in the period from January 2016 to April 2016. The study was performed according to WMA Declaration of Helsinki-Ethical Principles for Medical Research Involving Human Subjects.

Criteria for patient's selection:

-No history of intraocular surgery such as cataract or glaucoma surgeries;

-No history of glaucoma disease or treatment-Normal (IOP) below $20 \mathrm{mmHg}$;

-Normal optic disc by fundus examination (No glaucomatous cupping).

Cases were subjected to the followings:

-Full medical history;

-General medical examination for fitness for general anesthesia;

-General surgical examination for surgical evaluation of gall bladder;

-Abdominal ultrasonography.

-Laboratory investigations including: Complete blood count (CBC), liver and kidneys functions tests, bleeding and clotting time and hepatitis B and C Elisa body's detection.

IOP measurement shortly from 6 - 12 hours preoperatively, intra-operatively and shortly 6 - 12 hours postoperatively using indentation tonometer (Shoitz tonometer) under topical anesthesia using (Benoxinate $\mathrm{Hcl}$ 0.4\%).

The operative procedure: Laparoscopic cholecystectomy under general inhalation anesthesia, reverse Trendelenburg position of the patient, $\mathrm{CO}_{2}$ abdominal insufflations ( $15 \mathrm{mmHg}$ ). The surgery was performed by one surgeon in all cases.

Statistical analysis for the data using One Way ANOVA was performed. 


\section{Results}

The demographic data of the patients revealed that $11(45.8 \%)$ were male and 13 (54.2\%) were female, age of patients ranged from 23 - 63 years with mean age $(44.54 \pm 11.53)$ years. All patients were studied bilaterally except one patient was single eyed.

As regarding to the pre-operative IOP in all patients the average IOP for both eyes was ranged from $(12.2-18.1) \mathrm{mmHg}$ with mean value $(15.21 \pm 1.61)$ $\mathrm{mmHg}$.

The study reported a significant elevation of intra-operatively IOP $(\mathrm{P}<0.001)$ in comparison to the preoperative measurements as the average IOP for both eyes was ranged from $(14-36.15) \mathrm{mmHg}$ with mean value $(24.55 \pm 6.28)$ $\mathrm{mmHg}$.

Also the study reported that the IOP returned nearly to the preoperative values shortly (6 - 12 hours) post-operatively as the average IOP for both eyes was ranged from $(12.2-21.5) \mathrm{mmHg}$ with mean value $(16.13 \pm 2.44) \mathrm{mmHg}$. It was insignificant difference $(\mathrm{P}>0.05)$ between the pre and the postoperative IOP measurements (Table 1 ).

The study revealed that there was positive correlation between age and intra-operative (IOP) $(\mathrm{r}=0.981),(\mathrm{P}<0.001)$ with high significant value, denoting that the older the age, the more liability for elevation of intra-operative (IOP) (Figure 1).

\section{Discussion}

IOP changes during laparoscopic cholecystectomy were contributed to many mechanisms, the most common factors affecting IOP during this surgery were abdominal $\mathrm{CO}_{2}$ insufflations and head down posture, but most surgeon prefer head up position (reverse Trendelenburg position) that has the little vascular and respiratory effects [4] [5].

This study was limited in evaluation of IOP in relation to $\mathrm{CO}_{2}$ insufflations, reporting a significant elevation of intra-operatively IOP in comparison to the preoperative measurements in the procedure with abdominal $\mathrm{CO}_{2}$ insufflations with reverse Trendelenburg position under general anesthesia, this results agree with Uno et al. (1994) [3] who reported similar results but under epidural block anesthesia, Marco et al. (1990) [1] stated that the different types of anesthesia during laparoscopic cholecystectomy had the minimal vascular effects on circulation and central venous pressure and this may explain the similarity in results between the present study and that of Uno et al. (1994) [3].

The present study reported a significant elevation of intra-operative (IOP) in spite of the reverse Trendelenburg position as head up, as the study of Swan et al. (1985) [8] and Park et al. (2016) [9] stated that the head elevation has lower IOP than supine position, the explanation of significant elevation in the present study may be attributed to abdominal $\mathrm{CO}_{2}$ insufflations that had the dominant effect rather head position and this explanation agreed by Uno et al. (1994) [3] and Hirvonen et al. (2000) [4]. 
Table 1. Demographic and IOP results.

\begin{tabular}{|c|c|c|c|c|c|c|c|c|c|c|c|}
\hline \multirow{2}{*}{ Patients } & \multirow{2}{*}{$\begin{array}{c}\text { Age } \\
\text { In years }\end{array}$} & \multirow{2}{*}{ Sex } & \multicolumn{3}{|c|}{ Preoperative IOP $\mathrm{mmHg}$} & \multicolumn{3}{|c|}{ Intra-operative IOP $\mathrm{mmHg}$} & \multicolumn{3}{|c|}{ Postoperative IOP mmHg } \\
\hline & & & Rt & Lt & Average & Rt & Lt & Average & Rt & Lt & Average \\
\hline 1 & 56 & M & 15.9 & 15.9 & 15.9 & 20.6 & 20.6 & 20.6 & 14.6 & 13.4 & 14 \\
\hline 2 & 42 & M & 17.3 & 15.9 & 16.6 & 20.6 & 22.4 & 21.5 & 18.9 & 17.3 & 18.1 \\
\hline 3 & 33 & $\mathrm{~F}$ & 13.4 & ------ & 13.4 & 15.9 & ------- & 15.9 & 13.4 & ------ & 13.4 \\
\hline 4 & 43 & $\mathrm{~F}$ & 18.9 & 15.9 & 17.4 & 18.9 & 18.9 & 18.9 & 17.3 & 15.9 & 16.6 \\
\hline 5 & 61 & F & 17.3 & 17.3 & 17.3 & 31.6 & 29 & 30.3 & 20.6 & 18.9 & 19.75 \\
\hline 6 & 55 & $\mathrm{~F}$ & 14.6 & 14.6 & 14.6 & 26.6 & 26.6 & 26.6 & 17.3 & 15.9 & 16.6 \\
\hline 7 & 43 & F & 13.4 & 15.9 & 14.65 & 29 & 31.6 & 30.3 & 20.6 & 20.6 & 20.6 \\
\hline 8 & 23 & M & 13.4 & 13.4 & 13.4 & 22.4 & 22.4 & 22.4 & 15.9 & 15.9 & 15.9 \\
\hline 9 & 28 & M & 13.4 & 13.4 & 13.4 & 22.4 & 22.4 & 22.4 & 15.9 & 15.9 & 15.9 \\
\hline 10 & 56 & $\mathrm{M}$ & 18.9 & 17.3 & 18.1 & 34.5 & 31.6 & 33.05 & 18.9 & 18.9 & 18.9 \\
\hline 11 & 45 & $\mathrm{~F}$ & 12.2 & 12.2 & 12.2 & 14.6 & 14.6 & 14.6 & 12.2 & 12.2 & 12.2 \\
\hline 12 & 44 & F & 13.4 & 14.6 & 14 & 13.4 & 14.6 & 14 & 13.4 & 14.6 & 14 \\
\hline 13 & 49 & $\mathrm{~F}$ & 17.3 & 17.3 & 17.3 & 31.6 & 31.6 & 31.6 & 18.9 & 17.3 & 18.1 \\
\hline 14 & 53 & $\mathrm{M}$ & 14.6 & 14.6 & 14.6 & 26.6 & 26.6 & 26.6 & 14.6 & 14.6 & 14.6 \\
\hline 15 & 55 & $\mathrm{M}$ & 15.9 & 15.9 & 15.9 & 29 & 29 & 29 & 17.3 & 17.3 & 17.3 \\
\hline 16 & 58 & F & 14.6 & 14.6 & 14.6 & 24.4 & 29 & 26.7 & 17.3 & 17.3 & 17.3 \\
\hline 17 & 26 & $\mathrm{~F}$ & 15.9 & 15.9 & 15.9 & 15.9 & 15.9 & 15.9 & 15.9 & 15.9 & 15.9 \\
\hline 18 & 29 & $\mathrm{M}$ & 14.6 & 14.6 & 14.6 & 29 & 26.6 & 27.8 & 14.6 & 14.6 & 14.6 \\
\hline 19 & 63 & M & 14.6 & 14.6 & 14.6 & 29 & 29 & 29 & 14.6 & 14.6 & 14.6 \\
\hline 20 & 34 & F & 13.4 & 14.6 & 14 & 24.4 & 26.6 & 25.5 & 13.4 & 13.4 & 13.4 \\
\hline 21 & 47 & F & 18.9 & 17.3 & 18.1 & 37.8 & 34.5 & 36.15 & 22.4 & 20.6 & 21.5 \\
\hline 22 & 48 & F & 15.9 & 15.9 & 15.9 & 15.9 & 15.9 & 15.9 & 15.9 & 15.9 & 15.9 \\
\hline 23 & 44 & $\mathrm{M}$ & 13.4 & 14.6 & 14 & 24.4 & 26.6 & 25.5 & 13.4 & 13.4 & 13.4 \\
\hline 24 & 35 & $\mathrm{M}$ & 14.6 & 14.6 & 14.6 & 29 & 29 & 29 & 14.6 & 14.6 & 14.6 \\
\hline Mean & $44.54 \pm 11.53$ & & & & $15.21 \pm 1.61^{\star}$ & & & $24.55 \pm 6.28^{\star *}$ & & & $16.13 \pm 2.44^{* * *}$ \\
\hline
\end{tabular}

One Way ANOVA, $\mathrm{F}=39.696 . \mathrm{P}<0.001$, between ${ }^{\star}$ and ${ }^{* \star}$ Significant. $\mathrm{P}>0.05$ between ${ }^{\star}$ and ${ }^{* *}$ Insignificant. $\mathrm{P}<0.001$ between ${ }^{* *}$ and ${ }^{* \star}$ Significant. Correlation between age and intra-operative IOP $\mathrm{r}=0.981^{* *} \mathrm{P}<0.001$.

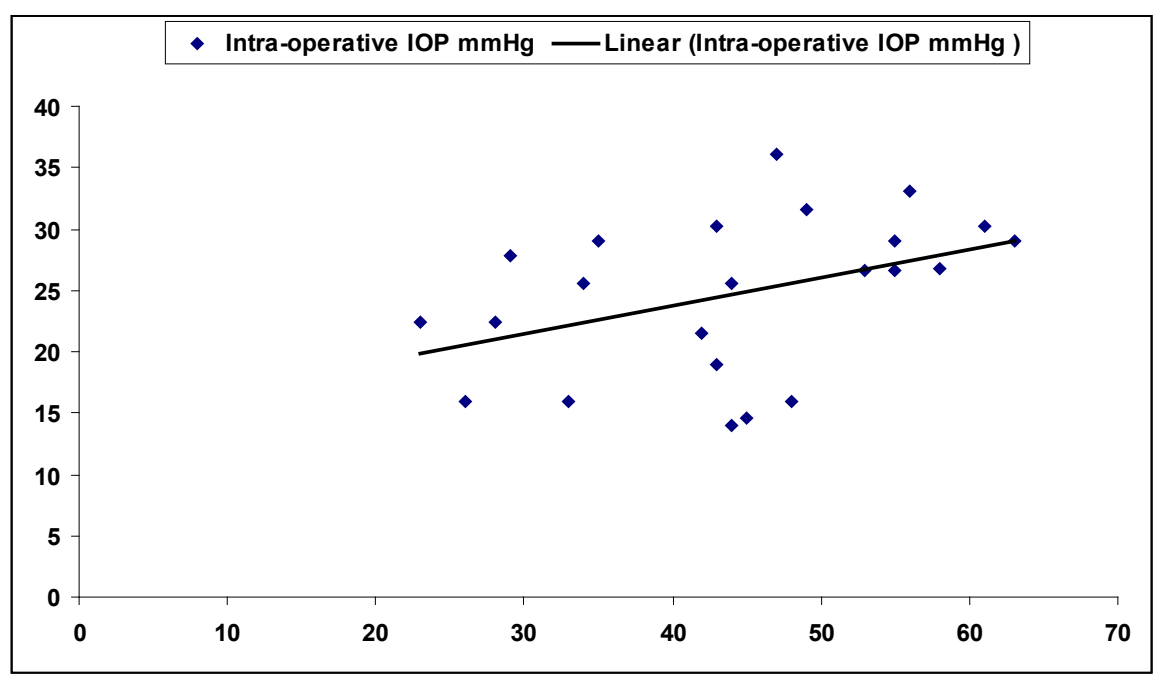

Figure 1. Correlation between age and intra-operative (IOP). 
The study revealed also that there was a positive correlation between age and intra-operative (IOP) which may be explained by the senile cardiovascular and atherosclerotic changes that may play a role in that result. Also, Cunningham et al. (1993) [2] and McLaughlin et al. (1995) [7] reported such cardiovascular and hemodynamic changes especially with aging during laparoscopic cholecystectomy.

\section{Conclusion}

During laparoscopic cholecystectomy surgery, IOP was significantly elevated in spite of the head up position which is not favorable for glaucoma or ocular hypertension patients. Head down position and old age patients also should be avoided as it may increase the risk of more IOP elevation. Further studies are needed on large numbers of patients to allow surgeons to re-evaluate the decision.

\section{Conflict of Interest}

The authors declare no conflict of interest.

\section{Acknowledgements}

The authors acknowledge Dr. Tamer Gamal Ophthalmology Department, Zagazig University for his revision of the study.

\section{References}

[1] Marco, A.P., Yeo, C.J. and Rock, P. (1990) Anesthesia for a Patient Undergoing Laparoscopic Cholecystectomy. Anesthesiology, 73, 1268-1270.

https://doi.org/10.1097/00000542-199012000-00029

[2] Cunningham, A.J., Turner, J., Rosenbaum, S. and Rafferty, T. (1993) Transoesophageal Echocardiographic Assessment of Hemodynamic Functions during Laparoscopic Cholecystectomy. British Journal of Anaesthesia, 70, 621-625. https://doi.org/10.1093/bja/70.6.621

[3] Uno, T., Hattori, S., Itoh, K., Taniguchi, K. and Honda, N. (1994) Intra-Ocular Pressure Changes during Laparoscopic Cholecystectomy. Masui, 43, 1899-1902.

[4] Hirvonen, E.A., Poikolainen, E.O., Pääkkönen, M.E. and Nuutinen, L.S. (2000) The Adverse Hemodynamic Effects of Anesthesia, Head-Up Tilt, and Carbon Dioxide Pneumoperitoneum during Laparoscopic Cholecystectomy. Surgical Endoscopy, 14, 272-277. https://doi.org/10.1007/s004640000038

[5] Koivusalo, A.M., Pere, P., Valjus, M. and Scheinin, T. (2008) Laparoscopic Cholecystectomy with Carbon Dioxide Pneumoperitoneum Is Safe Even for High-Risk Patients. Surgical Endoscopy, 22, 61-67. https://doi.org/10.1007/s00464-007-9300-2

[6] Hvidberg, A., Kessing, S.V. and Fernandes, A. (1981) Effect of Changes in $\mathrm{PCO}_{2}$ and Body Positions on Intraocular Pressure during General Anaesthesia. Acta Ophthalmologica (Copenhagen), 59, 465-475. https://doi.org/10.1111/j.1755-3768.1981.tb08331.x

[7] McLaughlin, J.G., Scheeres, D.E., Dean, R.J. and Bonnell, B.W. (1995) The Adverse Hemodynamic Effects of Laparoscopic Cholecystectomy. Surgical Endoscopy, 9, 121-124. https://doi.org/10.1007/BF00191950

[8] Swan, J.G., Phillips, S.D., Knaus, D.A., Kattamis, N.T., Toutain-Kidd, C.M., Zegans, 
M.E., Fellows, A.M. and Buckey, J.C. (1985) Acute Effects of Changes to the Gravitational Vector on the Eye. Journal of Applied Physiology, 15, 939-946.

[9] Park, J.H., Nam, K.T., Yoo, C. and Kim, Y.Y. (2016) Head Elevation and Intraocular Pressure in Glaucoma. Optometry \& Vision Science, 93, 1163-1170.

https://doi.org/10.1097/OPX.0000000000000895

\section{Scientific Research Publishing}

Submit or recommend next manuscript to SCIRP and we will provide best service for you:

Accepting pre-submission inquiries through Email, Facebook, LinkedIn, Twitter, etc. A wide selection of journals (inclusive of 9 subjects, more than 200 journals)

Providing 24-hour high-quality service

User-friendly online submission system

Fair and swift peer-review system

Efficient typesetting and proofreading procedure

Display of the result of downloads and visits, as well as the number of cited articles Maximum dissemination of your research work

Submit your manuscript at: http://papersubmission.scirp.org/

Or contact ojoph@scirp.org 